\title{
Realidade territorial de unidades familiares no semiárido brasileiro
}

\author{
Déa de Lima Vidal e Daniel Paraguay Alves Santos
}

Introdução

A atual estrutura agrária brasileira apresenta em síntese dois principais territórios que possuem diferentes peculiaridades de gestão e desenvolvimento: o da agricultura familiar e o do agronegócio. A principal diferença entre eles é que a agricultura familiar é fortemente baseada no capital ecológico (especialmente a natureza viva), enquanto o agronegócio se afasta progressivamente da natureza, utilizando insumos e outros fatores artificiais de crescimento que substituem os recursos naturais (Ploeg, 2009). Destacam-se ainda como características peculiares do agronegócio a presença da mão de obra assalariada, a monocultura, a necessidade da grande quantidade de terra e a produção com fins exógenos. Esse sistema agrícola e o modelo econômico preconizado pela globalização são responsáveis por reestruturar a produção e o território agrário brasileiro. Quanto à produção familiar o inverso é observado em relação a alguns parâmetros, isto é, a presença predominante de mão de obra familiar, a diversidade de culturas, a necessidade de pouca terra para a (re) produção e a produção basicamente para subsistência, em que apenas o excedente é comercializado (Elias, 2003).

Para a agricultura familiar, assim como para o agronegócio, a terra é um dos principais fatores de produção, mas com a diferença de que ela também reproduz a unidade familiar (UF)e estabelece uma relação muito maior de uso que de troca mercantilizada com a terra. Já a grande produção é totalmente dependente do mercado, 
e a maioria dos recursos, senão todos, são mobilizados por meio daqueles, entrando no processo produtivo como mercadorias. Desse modo, a família rural trabalha o necessário para suprir as necessidades, diferentemente, portanto, do que ocorre no processo de produção do agronegócio, cujo objetivo sempre é a obtenção do maior lucro possível. Portanto, é na base da estrutura interna da agricultura familiar que se encontra a distinção básica entre esses dois tipos conflitantes de territórios agrários no Brasil (Oliveira, 2011).

Os principais conflitos no campo brasileiro são motivados pelas disputas territoriais, sendo que o progresso do agronegócio é estimulado principalmente pelo aumento da escala da produção, o que muitas vezes é viabilizado pela aquisição de outras unidades produtivas, em sua maioria as pequenas propriedades (Ploeg, 2009). Pauta-se, nesse ponto, pela necessidade de luta, autonomia e progresso socioeconômico por parte da agricultura familiar, que procura defender seu território em razão das lutas camponesas e de uma produção positiva, sinais da resistência do campesinato contra a desterritorialização. Para resistir a esse processo, as famílias agricultoras procuram se territorializar de diversas formas, que se modificam, avançam ou refluem conforme as conjunturas econômicas, sociais e políticas (Fernandes et al., 2009) que permitirão ou não a organização territorial.

Heredia (1979) observa, em relação às pequenas unidades rurais pernambucanas, que a especificidade do território camponês, familiar, é ser, ao mesmo tempo, unidade de produção e unidade de consumo, porque os membros que a compõem estão ligados ao processo produtivo mediante laços de parentesco. Quanto ao espaço agrário cearense, discute-se que o Ceará assumiu, a partir da inserção passiva do Estado na economia e do consumo globalizado, um novo papel na divisão social e territorial do trabalho do Brasil, abrindo-se às influências exógenas e aos novos signos da economia globalizada. O governo do estado do Ceará, desde o final da década de 1980, tem concentrado suas ações no planejamento macroeconômico e na atração de investimentos em infraestrutura e criação favorável a novos arranjos do agronegócio, o que privilegia os territórios denominados “manchas irrigáveis” (Elias, 2003).

Essa expansão do agronegócio, guiada pelo discurso do progresso, prejudica grande parcela da população rural e a organização do território agrário cearense, na medida em que as áreas mais econômica e ambientalmente viáveis - manchas irrigáveis - são privilegiadas. Esses territórios, favorecidos pelo governo e encabeçados pelo agronegócio, acabam absorvendo grande parte dos investimentos e estabelecem uma configuração territorial desigual, pois beneficiam apenas alguns segmentos socioeconômicos e os espaços mais rapidamente suscetíveis a uma reestruturação (Idem).

Esses investimentos públicos e/ou privados ampliaram os contrastes espaciais e sociais, considerando os planos voltados aos territórios que facilitam a reprodu- 
ção do capital. Esses territórios seletos, também chamados de pontos luminosos (Santos, 1997), subespaços dinâmicos ou polos receptores de investimentos, estão concentrados em regiões como a metropolitana de Fortaleza e litoral, baixo e médio Jaguaribe, vale do Acaraú e municípios de Juazeiro do Norte, Crato e Barbalha (Lima et al., 2011).

No entanto, a família produtora, diante desse ambiente desarmônico, desses subespaços dinâmicos denominados “ambientes hostis” (Ploeg, 2009), luta por autonomia e progresso como uma forma de construção e reprodução de um meio de vida rural em contexto adverso, caracterizado por relaçóes de dependência, marginalização e privação. Ademais, a agricultura familiar está voltada para produzir socioeconomicamente tanto quanto possível sob as circunstâncias dadas o valor agregado (diferença entre o valor monetário dos bens produzidos e os custos técnicos da produção), e seu desenvolvimento visa, acima de tudo, a aumentar tal valor na unidade produtiva. Essa ampliação reflete a condição familiar: o ambiente hostil é enfrentado por meio da geração socioeconômica independente de renda no curto, médio e longo prazo.

\section{Território e territorialidade: conceitos e contribuições de Claude Raffestin}

O conceito de território para a geografia é um importante instrumento de leitura das dinâmicas existentes no espaço. Genericamente, entende-se por território o espaço ocupado, construído, administrado e utilizado pela sociedade; portanto, um espaço social ou concretamente construído por determinado grupo, como consequência da dinâmica de sua existência e de suas decisões.

Diante da relevância dessa categoria de análise para a geografia, muitos autores discorreram sobre o tema. Segundo o tradicionalista Ratzel, por exemplo, os "organismos que fazem parte da tribo, da comuna, da família, só podem ser concebidos junto a seu território" (1988, p. 74). Observa-se que o autor se alinhou aos paradigmas "biologicistas", uma vez que o território dos seres humanos é compreendido a partir dos vínculos que estabelece com o território de outras espécies. Já Sack (1986) afirmou que territorialidade é uma estratégia de controle multiescalar e temporal, e Santos (1997) introduziu a dimensão simbólica a partir do uso do território. Haesbaert (2001), por sua vez, fundiu as dimensões simbólica e material com base na na dominação jurídico-política, em que o território é visto como um espaço delimitado e controlado, por meio do qual se exerce poder, que na maioria das vezes é entendido como o poder político do Estado. Porém, o geógrafo Claude Raffestin (1993) já ressaltava que as relações de poder são elaboradas a partir de uma combinação de energia e informação que se entrelaçam em 
função de determinados objetivos. Seria preciso, então, identificar as relações de produção presentes na "imagem territorial”, ou seja, na forma resultante das ações e das intenções de atores sintagmáticos (atores que realizaram um programa). Ao decifrar-se essa imagem territorial, compreende-se também a estrutura profunda do território, além de todo o conjunto de energia e informação que o ator sintagmático utilizou para a comunicação entre os modos de produção e o espaço.

Assim, dentre as diversas contribuições científicas elaboradas acerca do assunto, destaca-se a de Claude Raffestin, pois, ao almejar-se uma aproximação com as relações socioeconômicas, faz-se necessária uma categoria essencial de poder utilizada por ele para a compreensão do território: "que não é possuído nem adquirido, mas simplesmente exercido".

O território para o autor é formado pelas relações de poder multidimensionais, ou seja, por um conjunto de relações sociais, econômicas e culturais, e tem a população na origem de todo o processo, pois dela parte toda a ação. Trata-se do espaço apropriado socialmente, onde se projetou um trabalho - energia e informação - e que, por consequência, revela relações marcadas pelo poder. O território apoia-se no espaço, mas não é o espaço, e sim uma produção a partir do espaço. Ora, a produção inscreve-se em um campo de poder (Raffestin, 1993). Observa-se que o autor procura deixar clara a diferença entre espaço e território. Para ele, o espaço é anterior ao território. Este se forma a partir do espaço, é o resultado de uma ação conduzida por um ator sintagmático em qualquer nível. Ao apropriar-se de um espaço concreta ou abstratamente (por exemplo, pela representação), o ator "territorializa” o espaço. Ademais, o território é uma parcela trabalhada do espaço. Para um marxista, o espaço não tem valor de troca, mas somente valor de uso. $\mathrm{O}$ espaço é, portanto, anterior, preexistente a qualquer ação. O espaço é, de certa forma, "dado" como se fosse uma matéria-prima; preexiste a qualquer ação. "Local" de possibilidades é a realidade material preexistente a qualquer conhecimento e a qualquer prática de que será objeto a partir do momento em que um ator manifeste a intenção de dele se apoderar.

Raffestin chega à conclusão de que o poder se enraíza no trabalho. Trata-se de uma combinação de energia e informação, em que energia pode se transformar em informação, isto é, em saber e práticas, e a informação pode permitir que se exerça essa energia; logo, o poder está relacionado com trabalho, que é a capacidade de transformar a natureza e as relações socioeconômicas (Marx, 1984). Assim, a territorialidade para o autor reflete a multidimensionalidade do vivido territorial pelos membros de uma coletividade nas sociedades em geral. Ressalte-se que todas elas são relações de poder, uma vez que existe interação entre os agentes que buscam modificar tanto as relações com a natureza como as relações sociais. 
A territorialidade é atribuída pelo espaço vivido cotidianamente pelo ator sintagmático em determinado território, ou seja, o conjunto de relações estabelecidas que, por sua vez, dão conteúdo ao território. Assim, ela adquire um valor bem peculiar. Raffestin (1993) define-a como um conjunto de relações que se originam em um sistema tridimensional "sociedade-espaço-tempo" em vias de atingir a maior autonomia possível, compatível com os recursos do sistema. É preciso atentar, nesse sentido, para uma dimensão social maior, pois a relação "sociedade-meio" deve ser enfocada pelo prisma da classe social e do contexto histórico. Cada sistema territorial segrega sua própria territorialidade.

A territorialidade, então, inscreve-se no quadro da produção e da troca. Para Raffestin, toda a produção do sistema territorial determina ou condiciona sua consumação. A territorialidade desse sistema está inserida em um quadro de tessituras, nodosidades e redes que criam vizinhanças, acessos e convergências. As tessituras são a área de exercício do poder, ou a área de seu enquadramento, portanto uma delimitação. Os nós ou pontos simbolizam a posição dos atores sintagmáticos, enquanto as redes são elementos que asseguram a comunicação entre os territórios, podendo ser abstratas ou concretas, invisíveis ou visíveis. A interpretação desse conjunto de relações permitirá chegar à origem e à dinâmica do poder e, consequentemente, ao cerne da produção do território.

Portanto, o arcabouço teórico concebido por Raffestin comporta o estudo da realidade territorial da agricultura familiar em geral e, em especial, de unidades familiares como as do município de Tauá, já que o estudo incorpora a análise da transformação da natureza via relações produtivas socioeconômicas, inscrevendo-se no quadro da produção e da troca. Esse arcabouço permitirá compreender o conjunto de relações presentes nesse sistema, que certamente apresenta suas peculiaridades que se refletirão nas imagens territoriais. Ademais, a identificação das relações entre as tessituras, os nós e as redes permitirá visualizar, ao menos parcialmente, a dinâmica territorial que aquelas unidades familiares estabelecem no seu território.

Os objetivos específicos deste trabalho para um conjunto representativo de unidades familiares do Distrito do Trici, município de Tauá, CE, foram: (i) caracterizar e discutir os fatores de maior relevância na composição de sua renda; (ii) agrupar as UFs de acordo com características socioeconômicas homogêneas; e (iii) identificar imagens territoriais através das principais atividades que contribuem para o processo de territorialidade e reprodução social dessas UFs agrupadas. 
Realidade territorial de unidades familiares no semiárido brasileiro, pp. 55-83

FIGURA 1

Mapa de localização geográfica da Macrorregião de Planejamento Cearense do Sertão dos Inhamuns (Estado do Ceará, Brasil)

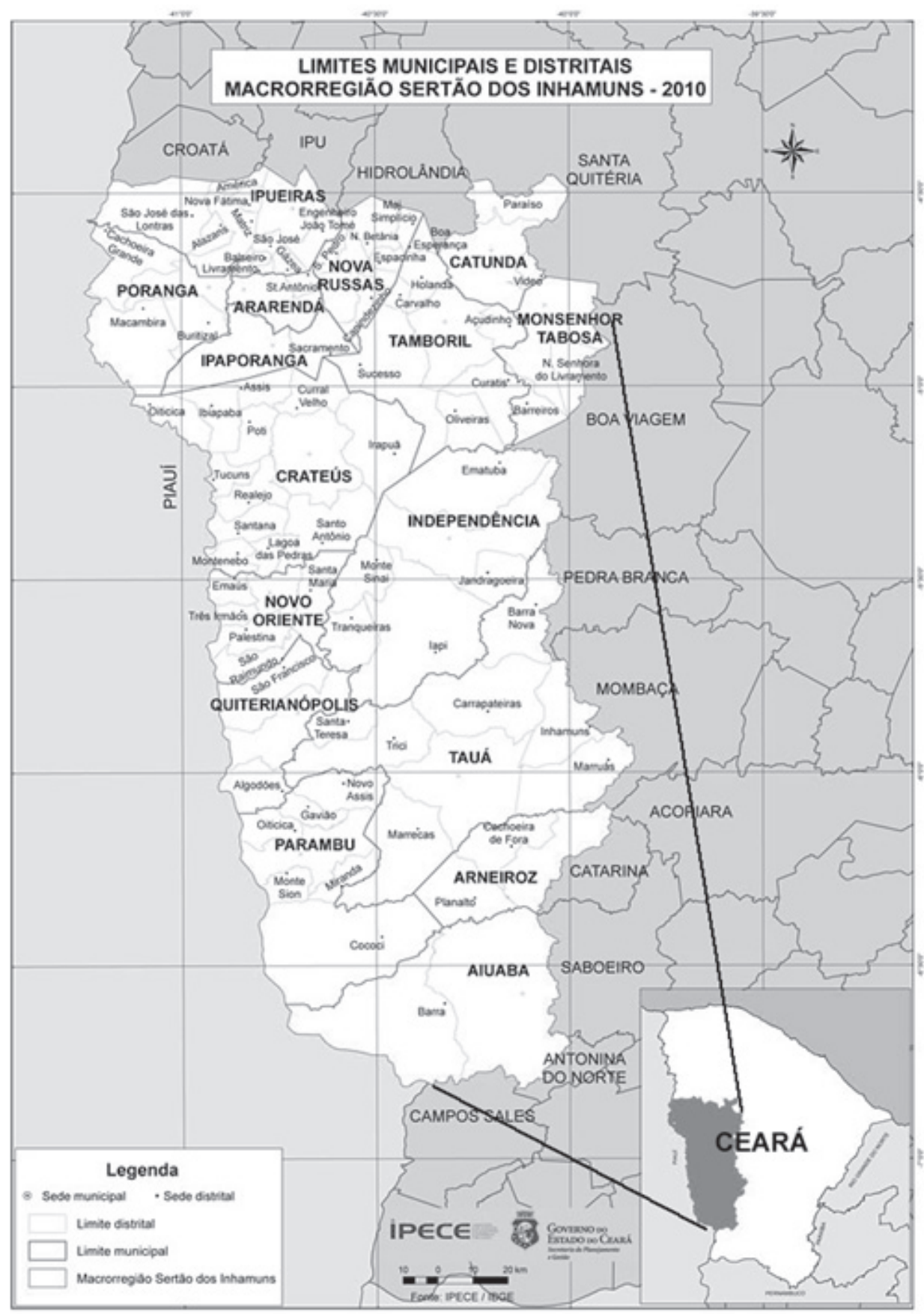

Fonte: Ipece (2010). 
Procedimentos metodológicos

Breve caracterização do Município de Tauá, no Ceará

O município de Tauá está situado na região semiárida; aproximadamente 46\% de sua população vive ainda na pobreza e metade do contingente populacional ( 56 mil habitantes, Ipece, 2010) situa-se em área rural praticando a agricultura familiar. No entanto, a renda média por estabelecimento rural é de apenas 1,7 mil reais por ano (França et al., 2002).

O município possui uma área de aproximadamente $4018,62 \mathrm{~km}^{2}$ e está situado na macrorregião de Planejamento Cearense do Sertão dos Inhamuns (Figura 1) (Ipece, 2010).

O seu Índice de Desenvolvimento Humano (IDH) apresenta média de 0,633, sendo que 9329 pessoas ainda vivem em situação de extrema pobreza (rendimento domiciliar per capita mensal de até setenta reais) na área rural do município (Ipece, 2011).

Genericamente, as comunidades rurais sob estudo apresentam algumas características microeconômicas comuns, como a baixa quantidade de terra, a superioridade do trabalho familiar e a predominância da produção vegetal. Dentre as principais potencialidades dessas comunidades, destacam-se a produção dos cereais milho e feijão por proverem a subsistência e parte da comercialização, bem como a criação de caprinos e ovinos, denominados pequenos ruminantes (Vidal e Alencar, 2009; Vidal, 2013; Vidal et al., 2014).

A diversidade animal e vegetal presente nas pequenas áreas agricultáveis das famílias rurais a priori é alta, pois o cultivo de várias espécies vegetais conjuntamente à pecuária proporcionaria essa elevada variedade biológica local sem necessidade de áreas de terra muito extensas (Altieri e Nicholls, 2002).

\section{Amostragem, variáveis e procedimentos de análise}

A coleta de dados originais e in situ foi realizada com base em questionário semiestruturado individualizado diretamente ao titular das UFs rurais (entre março e outubro de 2008). No total foram analisadas 96 ufs distribuídas entre seis comunidades rurais (Quadro 1) no distrito do Trici.

Com o intuito de propor alguns parâmetros para a compreensão do território familiar no semiárido cearense foi elaborado um quadro analítico com atributos relativos à dinâmica socioeconômica das Ufs e agrupados em dimensões de análise. Para isso, foram utilizados de maneira interativa parâmetros que caracterizam a territorialidade, a peculiaridade da região e a problematização do tema. Foram de- 
terminadas 36 variáveis (Quadro 2) para apreender atributos relativos à dinâmica socioeconômica e produtiva das UFs. A seleção baseou-se em pesquisas desenvolvidas sobre a agricultura familiar em regiões semiáridas do Brasil (Tourrand et al., 1993; Souza Neto et al., 1995; Caron e Hubert, 2003; Holanda Júnior, 2006; Vidal e Alencar, 2009). Esses atributos são o reflexo da capacidade dos atores sintagmáticos, aqui entendidos como os membros das famílias rurais, de transformar a natureza por meio de relaçóes produtivas socioeconômicas (Marx, 1984) e dizem respeito, portanto, à territorialidade.

QUADRO 1

Distribuição e amostragem das unidades familiares sob estudo, de acordo com a comunidade

\begin{tabular}{l|c|c|c}
\hline $\begin{array}{c}\text { Comunidades } \\
\text { (Denominação) }\end{array}$ & $\begin{array}{c}\text { Unidades Familiares } \\
\text { Residentes (Número) }\end{array}$ & $\begin{array}{c}\text { Unidades Familiares } \\
\text { Participantes (número) }\end{array}$ & $\begin{array}{c}\text { Unidades Familiares } \\
\text { Participantes (\%) }\end{array}$ \\
\hline Junco & 80 & 22 & 27,50 \\
Lustal 1 & 60 & 19 & 31,67 \\
Lustal 2 & 50 & 8 & 16,00 \\
Queimadas & 32 & 10 & 31,25 \\
Tapera & 53 & 22 & 41,51 \\
Tiassol & 30 & 15 & 50,00 \\
\hline Total & 305 & 96 & 31,48 \\
\hline
\end{tabular}

Fonte: Elaboração própria.

Inicialmente as variáveis socioeconômicas e produtivas foram submetidas à análise de componentes principais, permitindo a identificação dos fatores mais importantes que contribuem para a formação da "imagem territorial" da região. As coordenadas fatoriais geradas formaram a base para a análise subsequente, isto é, a análise de agrupamento (Rogerson, 2012), que permitiu a aproximação de UFs com atributos e capacidades semelhantes, evidenciando diferentes grupos de imagens territoriais, explicados por intermédio de suas territorialidades vivenciadas cotidianamente. 
Resultados e discussão

Análise de componentes principais aplicada aos resultados microeconômicos das unidades familiares das respectivas comunidades rurais

Na sequência são apresentados os resultados da análise de componentes principais que permitiram caracterizar e discutir os fatores socioeconômicos e produtivos de maior relevância na composição da renda do conjunto de unidades familiares sob estudo. Quatro componentes explicam 69,63\% do total da variância original.

O primeiro fator explica $28,87 \%$ da variância e relaciona a importância da produção vegetal e sua produtividade em relação ao trabalho para a obtenção de bons resultados microeconômicos. Esse fator é composto pelas variáveis de renda (valor agregado bruto $[\mathrm{VAB}]$ e valor agregado líguido [VAL] anuais), produção vegetal e produção vegetal/unidade de trabalho agrícola (UTA) total e caracteriza a existência de relações econômicas que permitiram a determinadas UFs atingirem resultados positivos com a concentração do trabalho (familiar e assalariado) na produção vegetal.

O segundo fator explica 16,95\% da variância original e identifica a existência de Ufs que conseguiram, em virtude da elevada rentabilidade do trabalho, minimizar seus gastos totais, fixos e variáveis. Esse fator é composto pelas variáveis "gastos totais", "gastos fixos", "gastos variáveis" e "produtividade do trabalho" (vAL/UTA total). Assim, o fator ressalta que a alta produtividade do trabalho total demonstra que os tipos de mão de obra presentes nas UFs, sejam elas familiares ou assalariadas, trabalham bem suas respectivas superfícies agrárias úteis (sAUs) e conseguem delas obter resultados econômicos positivos. Ressaltam-se a mão de obra familiar e sua importância nessas UFs, pois ela proporciona parcialmente a redução dos gastos fixos, variáveis e totais, na medida em que não há despesas com mão de obra assalariada, já que a de cunho familiar supre a necessidade no labor da terra.

O terceiro fator explica $14,16 \%$ da variância original e identifica a existência de UFs que obtiveram alta rentabilidade das superfícies agrárias úteis, mesmo apresentando baixa renda bruta (VAB) e baixa produtividade da terra em relação ao trabalho. Esse fator é composto pelas variáveis "produtividade da terra em relação ao trabalho total e familiar" (UTA total/sAu, uTA fam/sAU), "rentabilidade da terra" (VAL/SAU) e "gastos fixos" e demonstra que certas unidades familiares possuem uma baixa SAU, que está sendo trabalhada intensamente por muitas pessoas. Mesmo com elevada UTA total nessas UFs, elas apresentaram baixo VAB anual, pois possuem limitada área agricultável, inviabilizando maiores quantitativos nas produções. Destaca-se que a mão de obra familiar é a predominante e 


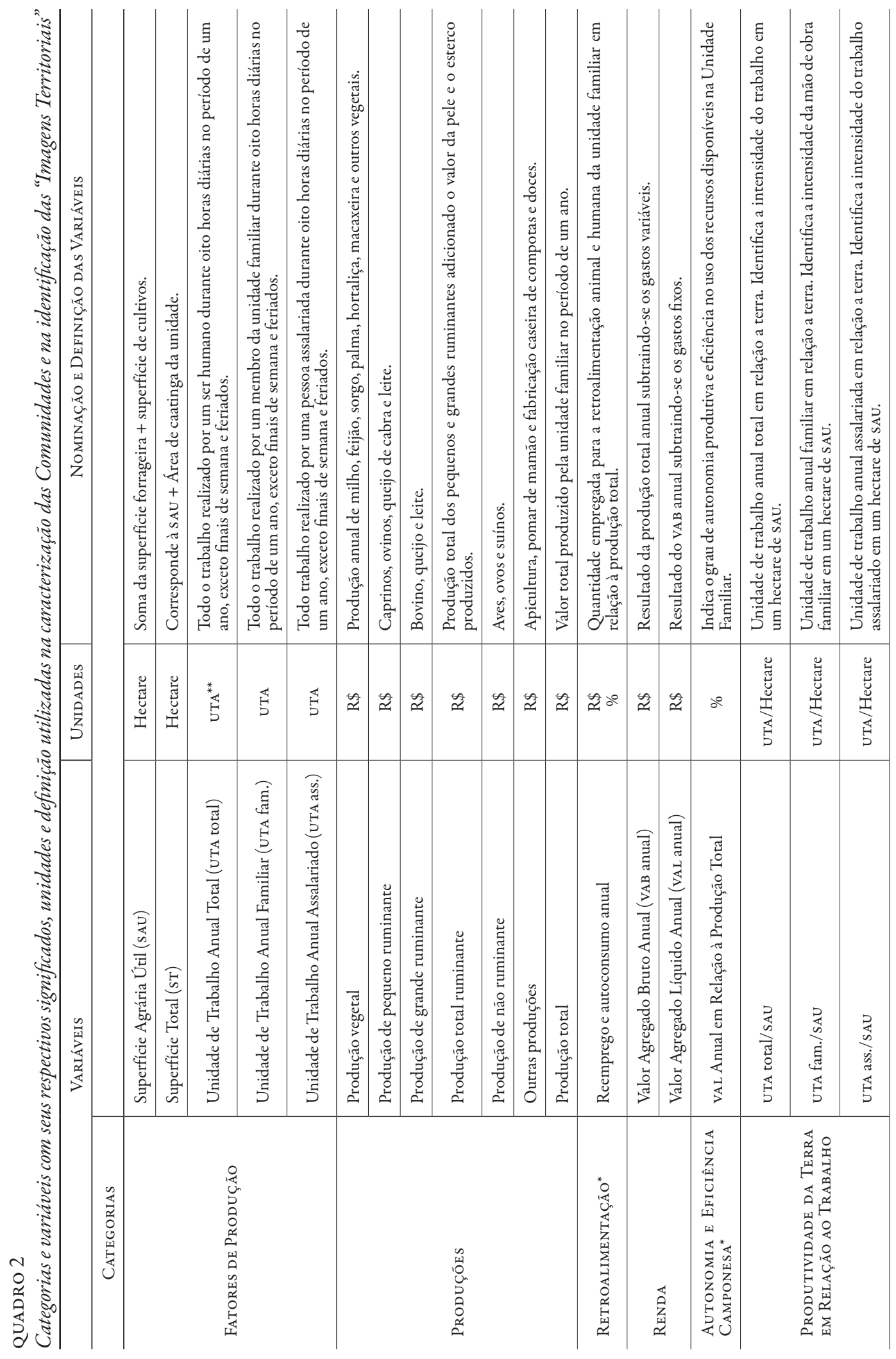




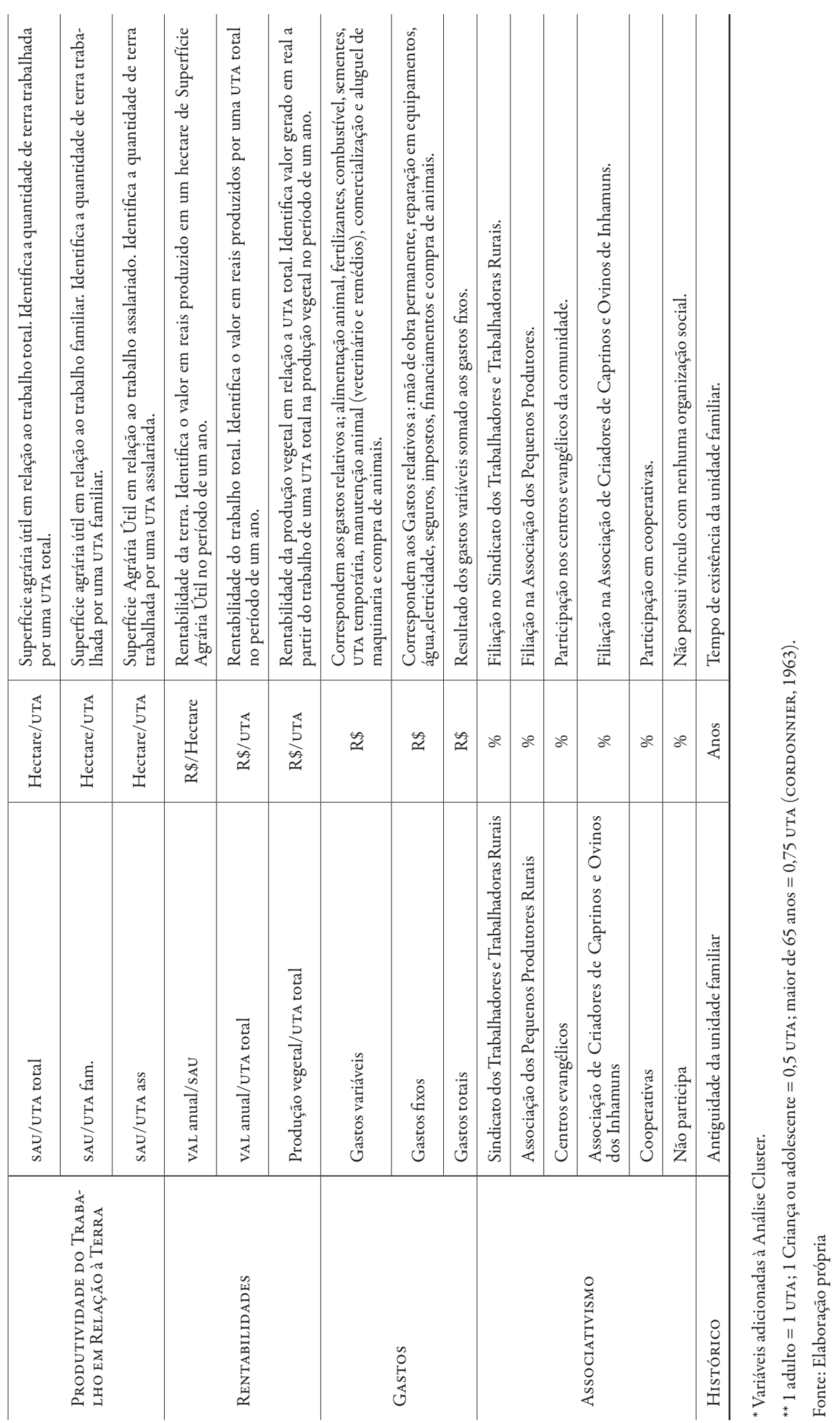




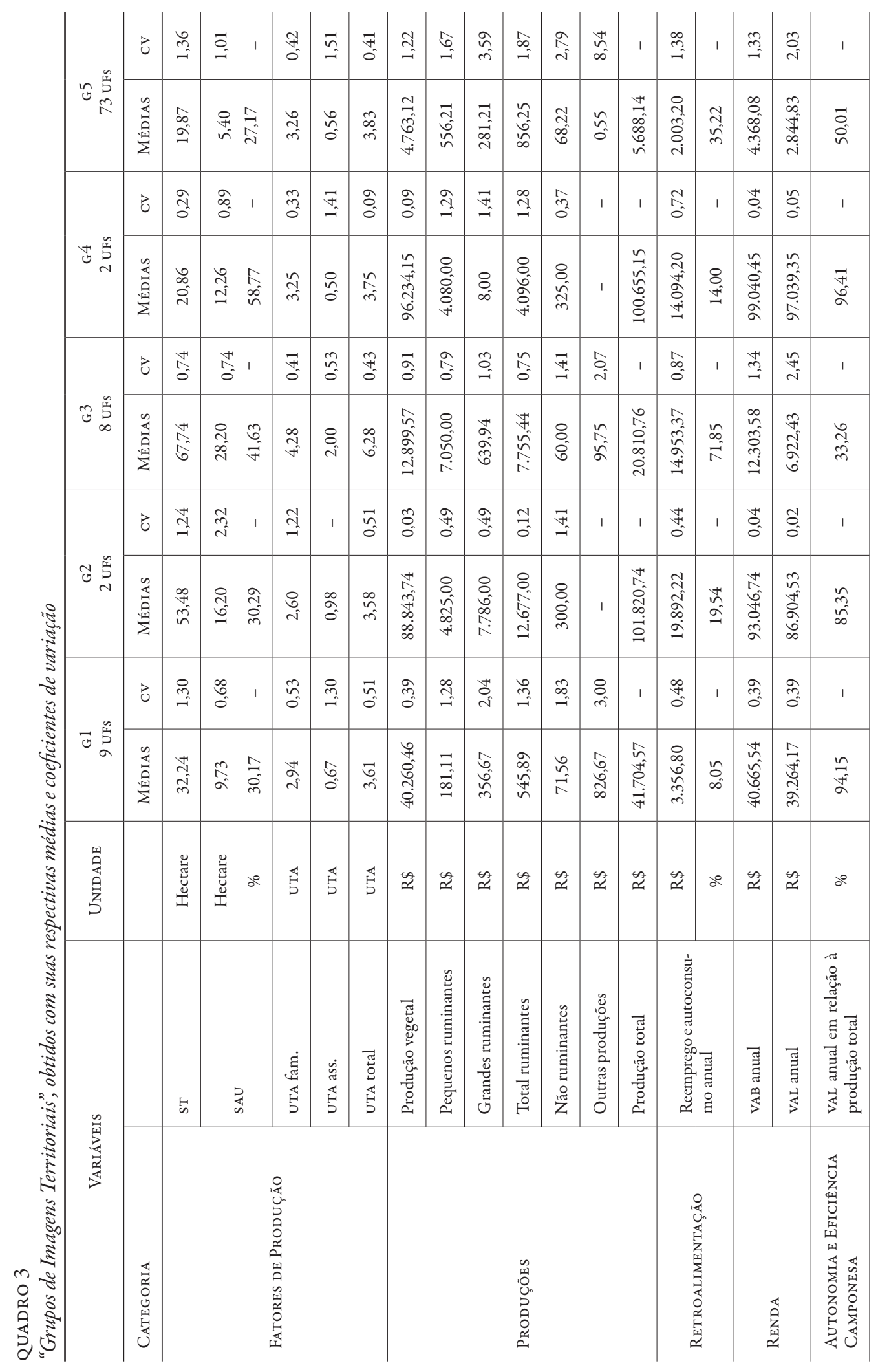




\begin{tabular}{|c|c|c|c|c|c|c|c|c|c|c|c|c|c|c|c|c|c|c|}
\hline $\begin{array}{l}\stackrel{0}{0} \\
\hat{0}\end{array}$ & $\begin{array}{l}2 \\
\hat{0}\end{array}$ & $\begin{array}{l}\stackrel{\text { I }}{0} \\
\text { - }\end{array}$ & $\stackrel{0}{-}$ & $\stackrel{\approx}{\leftrightarrows}$ & $\begin{array}{l}n \\
\tilde{o} \\
\tilde{s}\end{array}$ & $\stackrel{\hat{\sigma}}{\rightarrow}$ & $\stackrel{\infty}{\rightarrow}$ & તે & $\begin{array}{l}\hat{o} \\
\hat{o}\end{array}$ & $\begin{array}{l}\infty \\
\infty \\
0\end{array}$ & $\begin{array}{l}\hat{A} \\
\hat{0}\end{array}$ & $\hat{\imath}$ & 1 & 1 & 1 & 1 & 1 & 1 \\
\hline $\overrightarrow{\hat{0}}$ & $\begin{array}{l}8 \\
0 \\
0\end{array}$ & $\begin{array}{l}0 \\
0 \\
0\end{array}$ & $\underset{\sim}{-}$ & $\stackrel{\tilde{n}}{\sim}$ & $\begin{array}{l}\overrightarrow{5} \\
\sigma\end{array}$ & 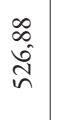 & 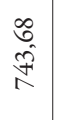 & 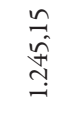 & $\begin{array}{l}\overrightarrow{\vec{n}} \\
\hat{\sim} \\
\stackrel{n}{n}\end{array}$ & 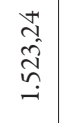 & 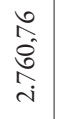 & $\begin{array}{l}\hat{\hat{i}} \\
\hat{i}\end{array}$ & $\underbrace{\infty}_{0}$ & $\begin{array}{c}2 \\
\dot{\infty} \\
\text { के }\end{array}$ & $\hat{\alpha}$ & $\stackrel{+}{\stackrel{*}{i}}$ & 1 & $\exists$ \\
\hline$\underset{\sim}{\stackrel{2}{二}}$ & $\hat{\sigma}$ & $\overrightarrow{\vec{\sigma}}$ & $\stackrel{\infty}{\infty}$ & $\begin{array}{l}8 \\
0 \\
0\end{array}$ & $\stackrel{2}{0}$ & $\hat{\tilde{n}}$ & $\underset{-}{\overrightarrow{0}}$ & $\overrightarrow{0}$ & $\begin{array}{l}\hat{b} \\
0\end{array}$ & $\begin{array}{l}n \\
\hat{0}\end{array}$ & $\underset{f}{O}$ & $\underset{0}{*}$ & 1 & 1 & 1 & 1 & 1 & 1 \\
\hline $\overrightarrow{m_{2}}$ & $\begin{array}{l}\hat{\lambda} \\
0\end{array}$ & $\begin{array}{l}* \\
0 \\
0\end{array}$ & $\begin{array}{l}\hat{\lambda} \\
\hat{n}\end{array}$ & $\begin{array}{c}\hat{n} \\
\hat{n}^{2}\end{array}$ & \begin{tabular}{l}
$\tilde{N}$ \\
\multirow{\sim}{\sim}{}
\end{tabular} & $\begin{array}{l}\frac{a}{n} \\
\frac{\pi}{\Omega} \\
\stackrel{n}{n}\end{array}$ & $\begin{array}{l}\overrightarrow{0} \\
\stackrel{1}{1} \\
\infty \\
\ddot{\sim}\end{array}$ & 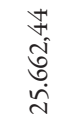 & 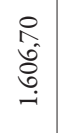 & $\begin{array}{l}\stackrel{0}{0} \\
\vec{i} \\
i \\
i\end{array}$ & $\begin{array}{l}8 \\
\infty \\
0 \\
0 \\
\dot{r} \\
\dot{r}\end{array}$ & $\begin{array}{l}\text { ñ } \\
\text { } \\
\stackrel{+}{+}\end{array}$ & in & 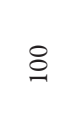 & 1 & in & 1 & 1 \\
\hline$\stackrel{\overrightarrow{5}}{-}$ & $\stackrel{\stackrel{q}{q}}{-}$ & $\stackrel{\Omega}{=}$ & $\begin{array}{l}0 \\
\stackrel{0}{0}\end{array}$ & $\begin{array}{l}0 \\
0 \\
0\end{array}$ & $\underset{-}{\stackrel{8}{-}}$ & $\begin{array}{l}\stackrel{\infty}{\infty} \\
\stackrel{\infty}{n}\end{array}$ & $\stackrel{\vec{m}}{m}$ & $\begin{array}{l}\vec{\infty} \\
0 \\
0\end{array}$ & $\begin{array}{l}n \\
\hat{o}\end{array}$ & $\overrightarrow{\sigma_{0}}$ & $\hat{\tilde{o}}$ & $\stackrel{2}{\circ}$ & 1 & 1 & 1 & 1 & 1 & I \\
\hline $\begin{array}{l}\text { הี } \\
\text { ô }\end{array}$ & $\frac{n}{0}$ & $\hat{0}$ & $\underset{+}{\stackrel{a}{+}}$ & $\hat{\hat{\sigma}}$ & $\stackrel{\circ}{\stackrel{+}{+}}$ & 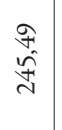 & $\begin{array}{l}\stackrel{\infty}{0} \\
\stackrel{1}{0} \\
\stackrel{-}{-}\end{array}$ & $\begin{array}{l}0 \\
\stackrel{0}{0} \\
\hat{0} \\
i \\
i\end{array}$ & $\begin{array}{l}\underset{\infty}{\infty} \\
\underset{+}{+} \\
\underset{\infty}{+} \\
\infty\end{array}$ & 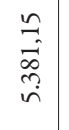 & 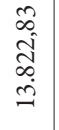 & $\begin{array}{l}\stackrel{n}{n} \\
\infty \\
\infty^{\circ}\end{array}$ & $\approx$ & 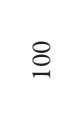 & 1 & $\begin{array}{l}8 \\
\text { in } \\
4\end{array}$ & 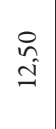 & 1 \\
\hline $\begin{array}{l}\vec{\infty} \\
0_{0}\end{array}$ & $\hat{\hat{\sigma}}$ & $\stackrel{\Delta}{\vec{n}}$ & $\stackrel{f}{=}$ & $\begin{array}{l}\tilde{0} \\
\stackrel{0}{0}\end{array}$ & $\stackrel{\Rightarrow}{\Rightarrow}$ & $\underset{\rightarrow}{\rightarrow}$ & $\stackrel{2}{\stackrel{0}{0}}$ & $\hat{\tilde{o}}$ & ते & $\begin{array}{l}n \\
\tilde{0} \\
\tilde{0}\end{array}$ & $\begin{array}{l}8 \\
:\end{array}$ & $\frac{0}{0}$ & 1 & 1 & 1 & I & 1 & 1 \\
\hline $\begin{array}{l}\text { ה̃ } \\
\text { ó }\end{array}$ & 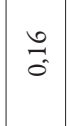 & $\begin{array}{l}8 \\
\Xi_{0}\end{array}$ & $\stackrel{\tilde{n}}{\hat{\sigma}^{\prime}}$ & $\begin{array}{l}\text { तु } \\
\text { S. }\end{array}$ & \begin{tabular}{l}
\multirow{2}{*}{} \\
\multirow{6}{6}{}
\end{tabular} & $\begin{array}{l}\vec{b} \\
\overrightarrow{0} \\
0 \\
i n \\
i n\end{array}$ & 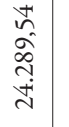 & 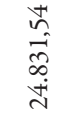 & $\begin{array}{l}8 \\
\infty \\
\infty \\
\infty \\
\infty \\
\infty\end{array}$ & $\begin{array}{l}\vec{J} \\
\vec{I} \\
\vec{G}\end{array}$ & $\begin{array}{l}\overrightarrow{\vec{N}} \\
\stackrel{0}{0} \\
\infty \\
\stackrel{+}{+}\end{array}$ & $\begin{array}{l}8 \\
\text { ô } \\
\text { in }\end{array}$ & in & 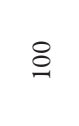 & 1 & 1 & 1 & 1 \\
\hline$\stackrel{\cong}{\leftrightarrows}$ & ஃ. & $\stackrel{\vec{n}}{\hat{i}}$ & $\stackrel{\infty}{\stackrel{0}{-}}$ & $\underset{\sim}{\tilde{-}}$ & $\tilde{m}$ & $\begin{array}{l}\infty \\
\stackrel{\infty}{o} \\
\hat{o}\end{array}$ & : & $\stackrel{\infty}{0}$ & $\stackrel{0}{:}$ & $\begin{array}{l}\infty \\
\stackrel{0}{0}\end{array}$ & $\stackrel{0}{2}$ & $\hat{A}$ & 1 & 1 & 1 & 1 & 1 & 1 \\
\hline$\hat{3}$ & $\begin{array}{c}0 \\
\vdots \\
0\end{array}$ & $\hat{0}$ & $\begin{array}{l}a \\
i \\
i\end{array}$ & $\begin{array}{l}\delta_{1} \\
m_{2}^{2}\end{array}$ &  & 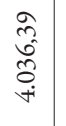 & $\begin{array}{l}\overrightarrow{0} \\
\hat{0} \\
\infty \\
\stackrel{0}{\oplus}\end{array}$ & $\begin{array}{l}\text { on } \\
\text { aे } \\
\stackrel{+}{=} \\
=\end{array}$ & 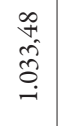 & $\begin{array}{l}\hat{m} \\
\overrightarrow{2} \\
\overrightarrow{+} \\
-i\end{array}$ & 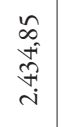 & $\begin{array}{l}8 \\
\stackrel{1}{4}\end{array}$ & $\exists$ & $\begin{array}{l}\hat{0} \\
\text { فे }\end{array}$ & $\vec{\exists}$ & 1 & 1 & $\begin{array}{l}\exists \\
\exists\end{array}$ \\
\hline 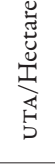 & 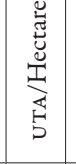 & 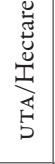 & 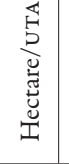 & 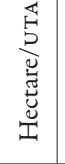 & 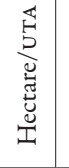 &  & 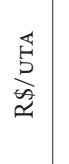 & $\frac{\overleftrightarrow{5}}{\stackrel{5}{2}}$ & $\widehat{\approx}$ & $\widetilde{\approx}$ & $\tilde{\approx}$ & 定 & $\therefore$ & $\therefore$ & $\alpha^{\circ}$ & de & $a^{\circ}$ & $\therefore$ \\
\hline 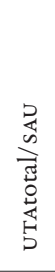 & 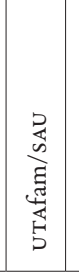 & 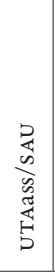 & 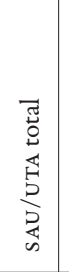 & 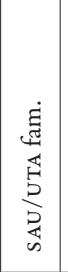 &  & 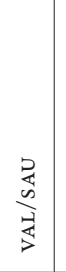 & 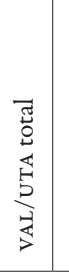 &  & 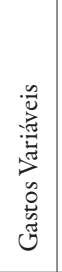 & 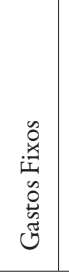 & 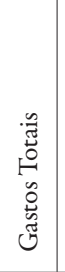 & 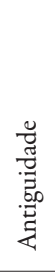 &  &  & 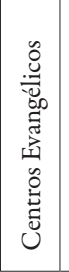 & 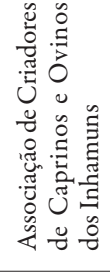 & 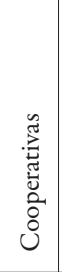 & 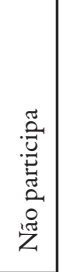 \\
\hline & 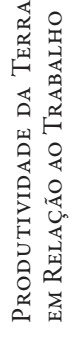 & & & 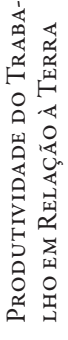 & & & 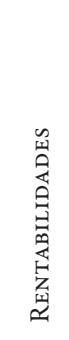 & & & $\begin{array}{l}0 \\
0 \\
0 \\
5 \\
\mathbb{5}\end{array}$ & & $\begin{array}{l}0 \\
0 \\
0 \\
o \\
0 \\
0 \\
0 \\
0\end{array}$ & & & 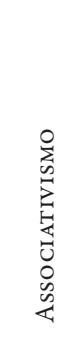 & & & \\
\hline
\end{tabular}


viabiliza resultados econômicos positivos para a rentabilidade da terra, mesmo em condições de insuficientes VAB e VAL anuais.

O quarto fator explica 9,95\% da variância original e identifica a existência de UFs que conseguiram minimizar seus gastos fixos. Esse fator é composto pelas variáveis "produtividade do trabalho total", "do trabalho familiar e assalariado" (sAU/UTA total, SAU/UTA fam., SAU/UTA ass., respectivamente) e "gastos fixos"; caracteriza a existência de UFs que apresentam uma alta SAU, trabalhada por baixa disponibilidade de mão de obra assalariada ou familiar. Essa relação entre os fatores de produção terra e trabalho reflete-se também nos baixos gastos fixos, pois os valores gastos com mão de obra assalariada são modestos, e a mão de obra de cunho familiar predomina.

Em todos os resultados da análise de componentes principais, observa-se que o trabalho apreendido como fator de produção está presente, sendo o principal responsável pela dinâmica econômica da pequena produção rural, juntamente com os aspectos relacionados com a terra, que na maioria das vezes limita uma maior produção. A questão do acesso a terra ainda é um grande entrave para o desenvolvimento socioeconômico da agricultura familiar brasileira, que procura em seu limitado território buscar meios e técnicas que viabilizem sua maior exploração para proporcionar sua manutenção e reprodução no campo. Esses fatores de maior relevância na composição da renda que estão na base das técnicas exercidas pela agricultura familiar de Tauá buscam uma maior exploração das áreas agricultáveis, que também têm limitações geoambientais, principalmente por estarem localizadas no ambiente da depressão sertaneja cearense, caracterizada por uma espessura dos solos pequena, grande frequência de afloramentos rochosos, alta salinidade do solo e uma pluviometria escassa e irregular (Sousa et al., 2005).

\section{Análise de agrupamento aplicada aos resultados microeconômicos das unidades familiares}

Apresentamos a seguir os resultados relativos a cada grupo de unidades familiares formados de acordo com sua similaridade socioeconômica e produtiva, doravante denominados "grupos de imagens territoriais" (Quadro 3).

Em todos os grupos, o trabalho familiar (UTA familiar) é predominante e o assalariado surge apenas como auxiliar em períodos de maior necessidade de mão de obra (Alves e Paulo, 2012). Esse fenômeno ocorre por causa da maior intensidade de atividades relacionadas com a semeadura, os tratos culturais e a colheita de cereais no período pós-chuvas iniciais, ou seja, de março a junho (Antonino et al., 2000).

- Grupo 1 de Imagens Territoriais: caracteriza-se por apresentar os melhores resultados para as outras produções e Ufs jovens que alcançam intermediária 
rentabilidade do trabalho total diretamente relacionada com a predominante produção vegetal.

- Grupo 2 de Imagens Territoriais: apresenta a segunda maior renda e a mais elevada produção de grandes ruminantes e uma das maiores produções vegetais, além da segunda mais alta produtividade do trabalho total em relação a terra.

- Grupo 3 de Imagens Territoriais: desfruta das maiores disponibilidades de terra e mão de obra e possui a produção vegetal como a principal atividade. Ademais, destaca-se pela mais alta produção de pequenos ruminantes. As UFs aglomeradas nesse grupo são muito antigas e alcançam a mais elevada produtividade do trabalho familiar em relação a terra.

- Grupo 4 de Imagens Territoriais: as Ufs mais antigas que possuem a mais elevada renda bruta e líquida anuais (VAB e VAL) concentram-se nesse grupo. O trabalho essencialmente familiar foca suas atividades na mais alta produção vegetal de todos os grupos e também apresenta os mais elevados resultados para a produção de não ruminantes. Ainda assim, as rentabilidades da terra, do trabalho total e da produção vegetal em relação à UTA total também alcançam seus resultados mais expressivos.

- Grupo 5 de Imagens Territoriais: caracteriza-se por aglomerar o maior número de UFs e apresentar as maiores produtividades da terra em relação ao trabalho total, familiar e assalariado que contrastam, no entanto, com as menores rendas. São as UFs mais jovens e que apresentam a segunda maior disponibilidade de UTA total e familiar.

\section{Território e territorialidade: a realidade de unidades familiares em Tauá}

Os grupos de imagens territoriais que exibiram as maiores áreas agricultáveis não foram necessariamente os que obtiveram maiores rendas: o G3 apresentou a maior média de SAU (28,20 ha) e apenas a quarta maior renda líquida (VAL anual). O grupo que obteve a maior renda líquida anual foi o G4, que em apenas 12,26 hectares conseguiu gerar o mais alto VAL anual ( $\mathrm{R} \$ 99.040,45)$, devido à boa rentabilidade do trabalho em relação à produção vegetal.

A produção vegetal está presente em todas as unidades familiares aglomeradas homogeneamente em grupos de imagens territoriais, sendo o principal meio de renda dessas famílias agricultoras que concentram suas atividades nessa cultura e no manejo específico de pequenos ruminantes. Isso evidencia a importância da produção cerealista no semiárido para o autoabastecimento, bem como para o suprimento das necessidades regionais, já que o município de Tauá se destacou como segundo maior produtor de feijão e o terceiro de milho do estado do Ceará (IBGE, 2007). 
O G3 e o G5, por não apresentarem uma boa produção vegetal, não conseguiram fortalecer suas respectivas rendas brutas (VABs anuais) e, consequentemente, suas rendas líquidas (VALs anuais). No G3 também foi identificada a maior quantidade de terra por UTA familiar, ou seja, existe uma quantidade razoável de terra trabalhada apenas por uma UTA familiar.

Quanto à produção animal, todos os grupos optaram pela criação de ruminantes. As outras produções apenas não foram identificadas no G2 e G4, que concentraram suas atividades na produção vegetal e aglomeraram as unidades familiares mais antigas.

Em todos os grupos, a UTA familiar é predominante, sendo que o trabalho assalariado também existe, mas entra apenas como auxílio quando há necessidade, normalmente de março a junho, devido aos tratos culturais dos cereais (Antonino et al., 2000). O grupo que melhor fez uso de sua superfície agrária útil foi o G4, que apresentou a maior rentabilidade da terra e também do trabalho e da produção vegetal em relação à disponibilidade de mão de obra total (UTA total). Inversamente, as menores rentabilidades foram observadas no $\mathrm{G} 5$, que ademais apresentou as menores produções vegetais e as menores produções animais, assim como as unidades familiares mais jovens. A baixa SAU influenciou diretamente essas modestas produções, pois esse grupo apresenta uma das menores quantidades de terra por UTA, ou seja, existe comparativamente um alto número de pessoas trabalhando em quantidade de terra limitada.

\section{A renda e a disponibilidade dos fatores de produção}

De acordo com a Articulação no Semiárido Brasileiro (Asabrasil, 2014), as contradições e as injustiças que permeiam o semiárido brasileiro podem ser compreendidas por meio da renda. A organização dos que dispõem de até um salário mínimo mensal soma mais de 5 milhões de pessoas (31,4\%). Enquanto isso, apenas 5,5\% dispõem de uma renda entre dois a cinco salários mínimos e 0,15\% com renda acima de trinta salários. Portanto, a grande maioria das pessoas residentes no semiárido brasileiro apresenta renda de até um salário mínimo (trezentos dólares aproximadamente para valor atualizado).

Esses baixos valores relativos à renda foram identificados nesse estudo. O Grupo 5 aglomerou o maior número de unidades e apresentou a menor renda. As 73 unidades familiares alcançaram o modesto rendimento mensal similar ao das mais de 5 milhões de pessoas evidenciadas pela Asabrasil (2014). Especificamente, as unidades familiares aglomeradas no G5 apresentaram uma renda líquida anual (VAL) de R\$ 2.844,83 (Gráfico 1), correspondendo a uma média mensal de apenas $\mathrm{R} \$ 237,06$, valor bem inferior a um salário mínimo. 
GRÁFICO 1

Renda anual em reais, relativa aos cinco grupos de imagens territoriais

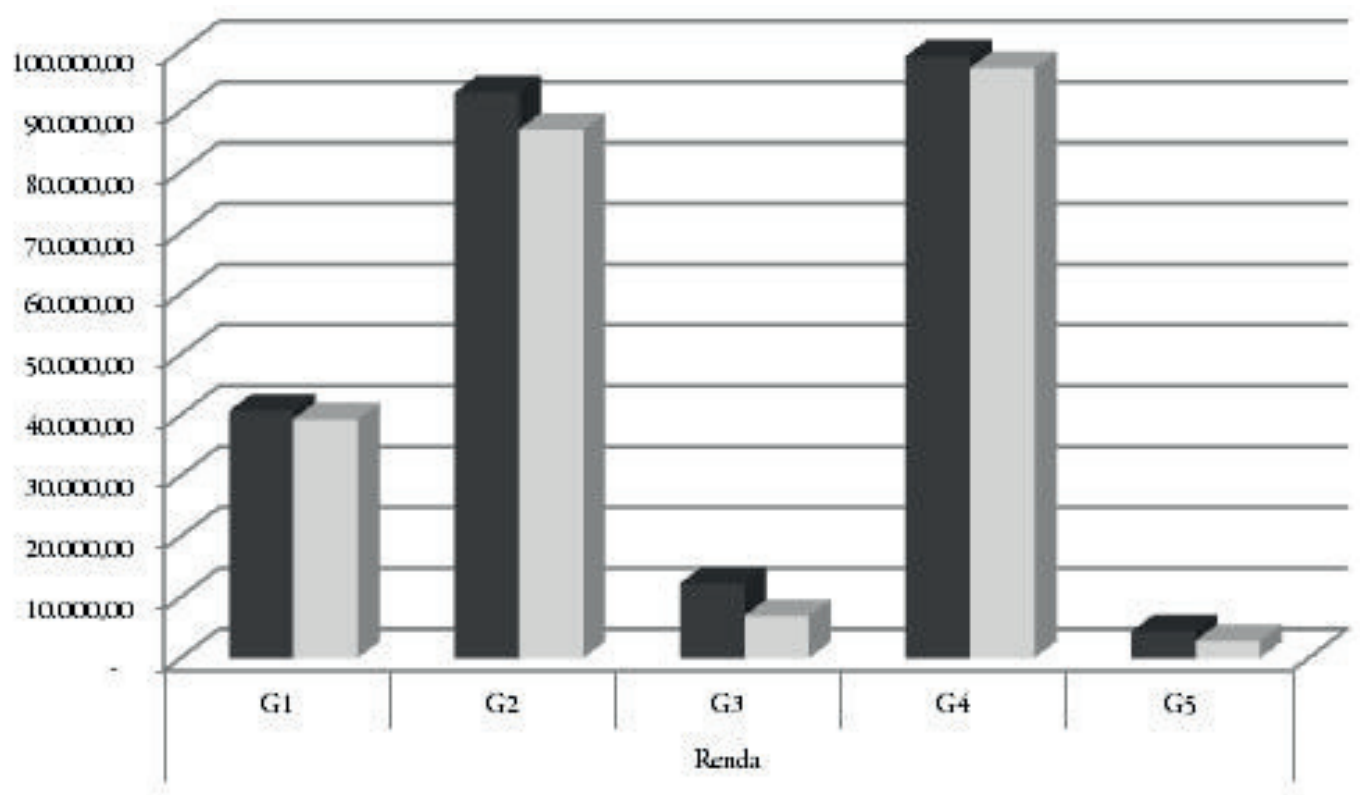

-VAB anual VAL anual

Fonte: Elaboração própria.

Em seu trabalho sobre agricultores familiares do estado de Sergipe, outra região semiárida brasileira, Lopes (2009) também identifica grande proporção de unidades com essa média de rendimento. Entre as 94 unidades familiares estudadas pelo autor, 26,6\% apresentaram rendimento entre um e dois salários-mínimos, enquanto 25,5\% se situam entre meio e um. Esse resultado assemelha-se aos das unidades familiares aglomeradas no G5 (Gráfico 1).

Em relação à quantidade de terra e de unidades familiares no semiárido brasileiro, a Asabrasil (2014) destaca que esse compreende uma área de $900 \mathrm{mil} \mathrm{km}^{2}$, onde estão presentes 2 milhões de estabelecimentos familiares, os quais correspondem aproximadamente à metade do universo da agricultura familiar do país, mas apenas $4,2 \%$ do total da área agrícola nacional. Esses dados revelam a enorme concentração de terra na região, configurando uma realidade socialmente injusta, na qual os latifúndios improdutivos dominam a paisagem, deixando as pequenas propriedades familiares com uma extensão de terra inviável para a sustentabilidade da agricultura familiar na região.

O G5, como previamente comentado, aglomerou o maior número de unidades familiares, expressando, portanto, a realidade das famílias estudadas. Esse grupo apresentou em média apenas 19,87 ha para a superfície total (ST), onde apenas 5,40 se configuram como SAU (Gráfico 2). 
GRÁFICO 2

Disponibilidade dos fatores de produção de acordo com os grupos de imagens territoriais

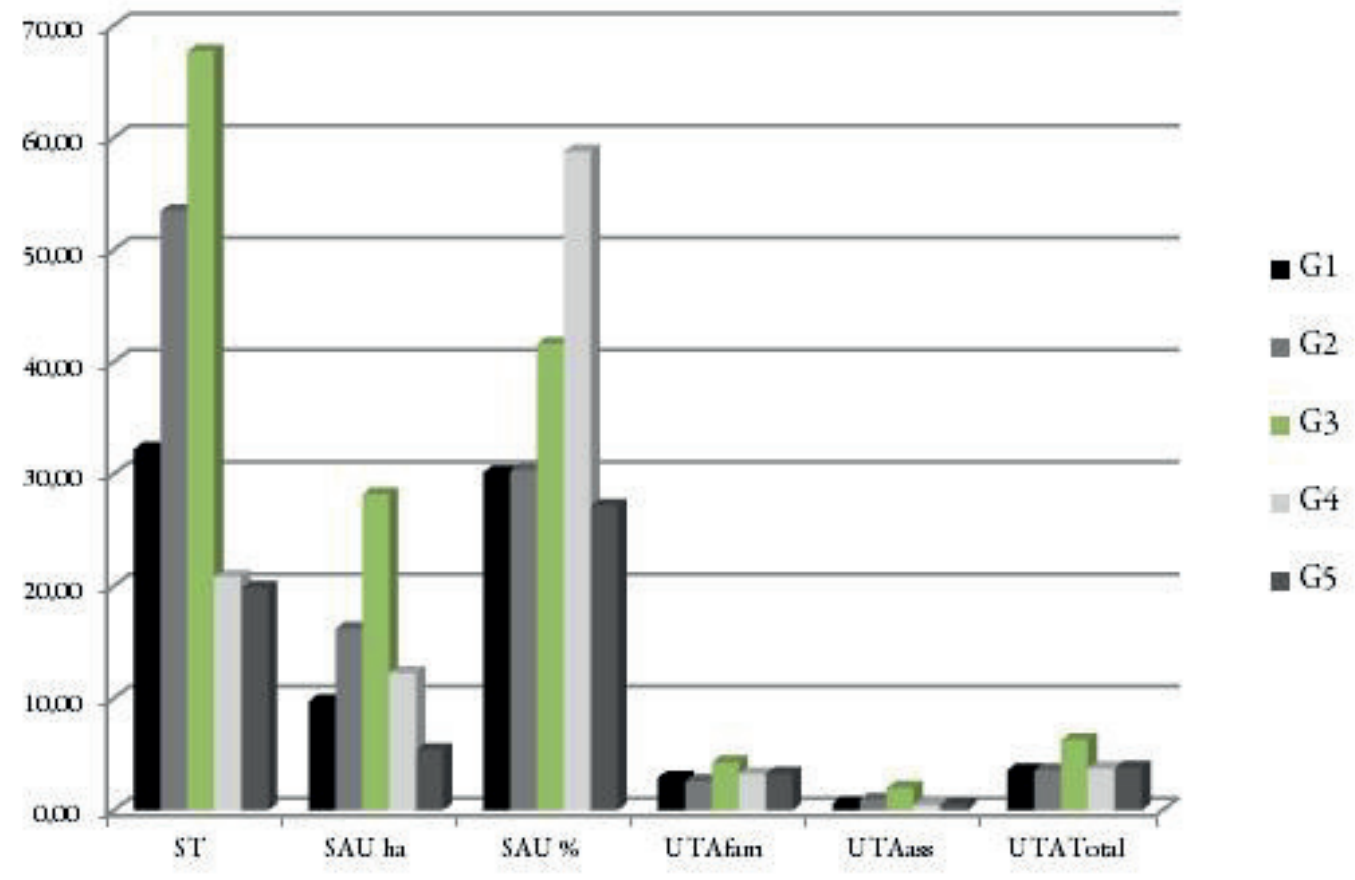

Fonte: Elaboração própria.

Ainda no trabalho de Lopes (2009) foi identificada uma realidade inferior à das unidades familiares aglomeradas no G5. A maioria (32,7\%) das unidades familiares possui entre um e três hectares, enquanto $15,4 \%$ possui média similar ao do G5. Ressalta-se que em ambos os resultados o baixo rendimento mensal está relacionado com a pequena disponibilidade de terra. De acordo com a Asabrasil (2014), essa baixa disponibilidade de terra juntamente com limitações fazem com que a agricultura familiar seja historicamente mantida em uma situação de grande vulnerabilidade social. Ademais, essa dificuldade de ampliação de ST foi também verificada em outras regiões semiáridas do Nordeste brasileiro (Guimarães Filho, 2005) e em regiões gaúchas (Neumann e Silveira, 2000). Historicamente, a impossibilidade de aumento da superfície agrária útil está vinculada ao da superfície total que, por sua vez, é inviabilizada pela ausência do processo da reforma agrária no Brasil (Norder, 2014).

O agricultor familiar diante desse "ambiente hostil" luta por autonomia e progresso como uma forma de construção e reprodução do meio de vida rural, pois a agricultura familiar está voltada para produzir valor agregado tanto quanto possível. Além disso, seu desenvolvimento visa, acima de tudo, a aumentar esse valor na unidade produtiva, já que ele reflete a condição camponesa da família: o “ambiente 
hostil" é enfrentado por meio da geração independente de renda no curto, médio e longo prazos. Assim, o valor agregado corresponde à nova riqueza gerada pelo trabalho da família agricultora no processo produtivo e se expressa na diferença entre o valor monetário dos bens produzidos e os custos técnicos da produção (consumos intermediários). O valor agregado é um importante indicador do grau de autonomia produtiva e de eficiência no uso dos recursos disponíveis nos sistemas agrícolas. Sistemas com altos valores de produção e baixo valor agregado empregam grande parte do seu faturamento na remuneração de agentes externos, como fornecedores de insumos e serviços (Ploeg, 2009).

\section{Autonomia e eficiência camponesa e o associativismo}

No estudo realizado em Tauá foi aplicada uma variável que permitiu identificar essa autonomia e eficiência camponesa, a saber: vAL anual em relação à produção total (Ploeg, 2009), tal como previamente abordado na metodologia. Essa variável apresentou resultados heterogêneos para os cinco grupos de "imagens territoriais" (Quadro 3). O grupo que obteve maior destaque foi o G4, pois apresentou a porcentagem de 96,41\% para aquela variável, sendo esse resultado reflexo da baixa remuneração dos agentes externos. Ainda assim, esse grupo apresentou a produção total anual de $\mathrm{R} \$ 100.655,15$. Como a remuneração dos agentes externos foi baixa, essa produção sofreu pouca redução e apresentou um VAL anual de R 97.039,35. Trata-se do grupo que atingiu a maior autonomia e eficiência camponesa, pois está realizando uma excelente utilização dos recursos disponíveis na unidade familiar e reduzindo seus gastos.

Os meios e os insumos são parte integrante do estoque disponível de capital ecológico da agricultura camponesa e não são adquiridos nos mercados como acontece na agricultura empresarial (Menezes, 2002). Mas em determinados grupos foi observado que essas autonomia e eficiência ainda não apresentam resultados satisfatórios. O Grupo 3 exibiu apenas 33,26\% de autonomia e eficiência camponesa, pois a elevada quantidade de agentes externos importada pelo grupo ainda é grande. Especificamente esse grupo importa uma quantidade elevada de alimentos que são utilizados para a manutenção dos pequenos ruminantes, pois as unidades familiares aglomeradas nesse grupo não conseguiram produzir o suficiente para o autoconsumo da família e dos animais. A produção total dessas famílias apresentou média anual de R $\$ 20.810,76$, e após a redução dos valores empregados em agentes externos a renda apresentada foi de somente $\mathrm{R} \$$ 6.922,43 por ano (Quadro 3).

Diferentemente do G3, o G1 também apresentou resultados elevados tal como o G4. As unidades familiares aglomeradas no G1 apresentaram 94,15\% de autonomia e 
eficiência camponesa, pois também conseguiram um reduzido gasto com os agentes externos. Esse grupo exibiu uma produção total de R \$ 41.704,57 e um VAL anual de $\mathrm{R} \$ 39.264,17$, ou seja, a diferença entre os valores é bem reduzida, diferentemente do G3, como já previamente comentado, e do G5, que apresentou apenas 50,50\% de autonomia e eficiência camponesa - esse último mais representativo em unidades familiares e também com a menor média para a renda líquida (VAL anual). Suas produções totais apresentaram média de $\mathrm{R} \$$ 5.688,14 e empregaram grande parte desses na remuneração de agentes externos, sendo que, ao final, o VAL anual apresentou média de apenas $\mathrm{R} \$ 2.844,83$. Portanto, a autonomia e a eficiência camponesa foram verificadas em seus maiores níveis no G4 e G1, enquanto as menores foram identificadas no G3 e G5. A emancipação, através do enfrentamento com êxito do “ambiente hostil", coincide necessariamente com a ampliação do valor agregado total por unidade de produção, pois decorre de um lento, porém persistente, aprimoramento da base de recurso e/ou melhoria da eficiência técnica (Ploeg, 2009). Isso significa que os territórios presentes no G1, particularmente, são quase independentes dos agentes externos. Ressalta-se que, embora a produção para o consumo familiar atenda em grande medida as necessidades alimentares desses atores sintagmáticos, há alimentos que não podem ser produzidos pela família e que são indispensáveis à manutenção dos territórios, necessitando, portanto, ser adquiridos. O G1, por outro lado, apresentou a menor produção de pequenos ruminantes, que pouco contribuiu para seu VAB anual, tal como foi colocado previamente. Por conta de sua adaptabilidade, existem grandes iniciativas de reestruturação dessa produção no município de Tauá. Isso significa que, ao inserir esses animais com mais intensidade na dinâmica de suas produções, os atores sintagmáticos poderão gerar um VAB mais elevado (Andrade e Lima, 2011; Bach et al., 2003).

Diante do exposto, identificou-se que apenas as UFs aglomeradas no G4 e G5 exibiram características que convergem com a emancipação colocada por Ploeg (2009). As UFs mais antigas conseguem aprimorar sua base de recursos e/ou melhorar a eficiência técnica. De fato isso foi observado nos resultados do presente trabalho, pois as UFs aglomeradas no G4 exibiram as maiores longevidades de assentamento, apesar da baixa disponibilidade de mão de obra assalariada e uma das menores de terra (Gráfico 2). Desse modo essas UFs do G4 conseguiram aprimorar, durante seus 44 anos de existência, sua limitada base de recursos fundiários (ST e SAU) e também melhoraram sua eficiência técnica, pois utilizam exclusivamente o trabalho familiar, não dependendo do trabalho externo para gerar a mais elevada renda, mesmo em limitada SAU.

Em relação às redes das UFs nas comunidades rurais, discute-se que essas também são locais de referência, sendo importante saber como os membros das UFs nas co- 
munidades se inter-relacionam com as demais, ou seja, aqueles membros que podem desenvolver uma sinergia para a cooperação mútua (Raffestin, 1993). Nos grupos de imagens territoriais, identificados pela análise de agrupamento, foi observado que a grande maioria das UFs se vincula politicamente às organizações sociais. O G5 e o G1 possuem a maior diversificação associativa, e apenas $4 \%$ das UFs do primeiro e 11\% das do segundo não possuem nenhuma filiação. Já no G2, G3 e G4 todas as UFs aglomeradas possuem filiação nas organizações sociais. Note-se que, entre as formas organizativas, a de maior relevância percentual para todos os grupos de imagens territoriais é a Associação dos Pequenos Produtores Rurais. Realmente, as associações são organizações mais flexíveis quando comparadas aos sindicatos, que se restringem às categorias profissionais reconhecidas. Os resultados obtidos corroboram os de Maneschy e Klovdahl (2007), pois existe uma grande diferença entre as porcentagens de filiados aos sindicatos e a porcentagem de filiações nas associações comunitárias, por exemplo. As afiliações nas associações, nos centros evangélicos, nos sindicatos, nas cooperativas e outros são de extrema importância para a compreensão da manutenção das relações sociais na composição de "imagens territoriais", pois qualquer forma de filiação é entendida como fator que colabora positivamente para uma organização sustentável de uma comunidade (Gomes, 2010).

Os atores sintagmáticos, ou seja, os membros da família rural, não se opõem; agem e, em consequência, procuram manter relações, assegurar funções, influenciar-se, controlar-se, interditar-se, permitir-se distanciar-se ou se aproximar e, assim, criar redes entre eles (Raffestin, 1993). De fato, as famílias rurais nas UFs agrupadas não se opõem, pois o propósito de manter as atividades agropecuárias e permanecer no meio rural impulsiona a união por meio do associativismo nas comunidades. Esse estreitamento entre as famílias e o objetivo em comum da manutenção no campo e da subsistência familiar influenciam diretamente a filiação das famílias rurais nas associações, nos sindicatos e nas cooperativas, pois viabilizam uma troca de experiências e saberes que são adquiridos no cotidiano de cada ator sintagmático, proporcionando assim uma ajuda mútua entre os territórios. Portanto, essa é uma das estratégias mais viáveis das famílias rurais na busca pela reprodução e defesa do seu território.

Diante da realidade territorial revelada pela análise de componentes principais previamente colocada, observa-se a presença do fator trabalho em todas as relações dos quatro fatores, confirmando que a dinâmica do poder nessas UFs realmente está enraizada no trabalho - o principal agente construtor da realidade dos territórios. A partir da realização e do controle do trabalho, as unidades familiares os adequam às suas realidades e procuram estabelecer um equilíbrio no intercâmbio de matérias com a natureza. A economia camponesa assenta-se nesse balanço, "consumo familiar versus exploração da força de trabalho". A relação entre trabalho e consumo passa pela 
satisfação das necessidades familiares que têm como limite a sobrevivência (Chayanov, 1974). Esse intercâmbio de matérias com a natureza explica a persistência e a sobrevivência de certas unidades familiares e a desagregação e o desaparecimento de outras (Schneider, 2003).

Mesmo que, em certos casos, as UFs estejam submetidas a determinados condicionantes externos como, por exemplo, o monopólio de preços ou os diferentes tipos de mercado, o fato de se estruturarem com base na utilização da força de trabalho de seus membros permite que algumas decisões se tornem possíveis, o que muitas vezes uma família agricultora muito inserida na dinâmica capitalista, contando com a contratação de assalariados, não poderia concretizar ou sofreria fortes restrições. De fato, a realidade pode ser observada mais especificamente no Grupo 4, que exibiu a menor quantidade de mão de obra assalariada, a maior média para a autonomia e eficiência camponesa e a mais elevada renda, viabilizando assim sua sobrevivência (Schneider, 2003). Essa economia familiar também possui uma grande flexibilidade de adaptação a diferentes crises e é um tipo de economia que não é menos poderosa, relevante ou influente, sendo capaz de resolver problemas tal qual a economia estatal ou a de mercado fazem (Shanin, 2008).

A agricultura familiar engloba um mosaico de agricultores familiares com distintos graus de desenvolvimento socioeconômico e também com diferentes lógicas de produção (Guanziroli et al., 2011). Portanto, a análise de agrupamento utilizada permitiu a aproximação de unidades familiares com atributos e capacidades dos atores sintagmáticos semelhantes, evidenciando diferentes grupos de imagens territoriais, explicadas por intermédio do conjunto de relações que dão conteúdo ao território.

As características detalhadas de cada grupo já foram apresentadas anteriormente; portanto, serão abordados agora apenas os aspectos mais relevantes para a compreensão, ao menos parcial, do processo de territorialidade e do conjunto de relações presentes no território que viabilizam a subsistência familiar.

\section{As produções vegetais e pecuárias e a retroalimentação}

A principal relação produtiva foi observada com a produção vegetal dos cereais milho e feijão, que está presente em todas as UFs e, portanto, em todas as “imagens territoriais, e é a atividade agrícola que proporciona os maiores resultados entre todas as produções em todos os grupos. $\mathrm{O}$ G3, além da produção vegetal, apresentou outra atividade que também caracteriza o processo de territorialidade das UFs aglomeradas ali. Trata-se da produção de pequenos ruminantes, que apresentam maior resistência a períodos de secas e são mais vantajosos para a comercialização comparativamente a outras produções pecuárias (Oliveira, 2011). Em seu trabalho sobre a produção 
camponesa e a sustentabilidade no campo, Oliveira ressalta que a introdução desse rebanho em assentamentos no município semiárido de Canindé, no Ceará, tem requerido aumento da quantidade de forragem, processo nem sempre compatível com a produção camponesa dos assentados. Essa realidade também foi observada no G3, que possui elevados gastos variáveis relativos à compra de ração para alimentação de pequenos ruminantes. Portanto, o problema da limitada forragem natural apresenta -se como um entrave para a subsistência familiar nos territórios do G3.

Em relação à retroalimentação, ou seja, ao reemprego e autoconsumo dessas famílias, o G5 apresentou a segunda maior porcentagem. Em seu trabalho sobre a agricultura familiar no Nordeste, Guanziroli et al. (2011) identificam os estados nordestinos onde os estabelecimentos familiares mais se dedicam ao autoconsumo, a saber: Piauí, Maranhão e Ceará. De acordo com os autores, esses estados também são os mais pobres do ponto de vista rural. Essa realidade, em diferente escala de análise, também foi observada no $\mathrm{G} 5$, pois esse grupo aglomera as unidades familiares com as menores rendas e com uma das maiores porcentagens de reemprego e autoconsumo. Deduz-se que a porcentagem de retroalimentação elevada está relacionada com o fato de a produção familiar ter como prioridade o consumo interno.

\section{A produtividade e a rentabilidade dos fatores de produção}

O G5 também apresentou elevadas disponibilidades de mão de obra (Quadro 3). A força de trabalho será sempre relativamente abundante, enquanto os meios de trabalho serão relativamente escassos na agricultura familiar (Neumann e Silveira, 2000). Isso significa que a produção familiar tende a ser intensiva em mão de obra. Essa intensidade foi observada no $\mathrm{G} 5$, responsável por apresentar a maior produtividade da terra em relação ao trabalho. Em média um hectare apresentou 0,71 de UTA total, 0,60 de familiar e 0,10 de assalariada. Essas médias são superiores às nacionais apresentadas recentemente por Guanziroli et al. (2011), que identificaram no ano de 2006 uma média de 0,12 UTA familiar por hectare e 0,01 de assalariada. Assim, os resultados encontrados no G5 demonstram que os territórios dessas unidades familiares, apesar de possuírem limitadas tessituras, que muitas vezes inviabilizam em parte a reprodução desses atores sintagmáticos, também apresentam elevada produtividade da terra, associada às intermediárias autonomia e eficiência camponesa, reemprego e autoconsumo e a grande diversidade organizacional.

Uma imagem territorial diferente foi observada nos territórios que compõem o G4. Esses apresentaram elevadas rendas e a mais alta produção de não ruminantes, a qual requer pouca quantidade de terra e, em grande parte, é cultivada nos quintais das unidades familiares. Vidal (2013) e Oliveira (2011) também identificam essas 
produções em seus estudos específicos no semiárido do estado do Ceará e evidenciam que as mulheres das unidades familiares são as principais responsáveis pelos cuidados com aves e/ou suínos (animais não ruminantes). Vidal (2013) também ressalta que o trabalho com essa produção pode ser potencializado pela mulher da unidade familiar, tornando-o uma atividade que pode colaborar significativamente para a renda familiar. Portanto, no G4 a produção vegetal foi a principal, mas o trabalho com os não ruminantes se apresenta como uma forma secundária de garantir a subsistência familiar e, consequentemente, o fortalecimento do território. Isso não beneficia somente o território, pois, diante da elevada e diversificada produção, a unidade familiar é capaz de atender tanto às necessidades do seu território como à do mercado interno (local, regional ou nacional).

A diversidade na produção tem favorecido a reprodução dos atores sintagmáticos e demonstra que as formas e os tipos de criação animal e cultivo vegetal se diferenciam no interior do conjunto de relações de cada grupo de territórios. O G2 também exibiu uma das mais elevadas rentabilidades da terra ( $\mathrm{R}$ \$ 5.365,61/ha) (Quadro 3). Guanziroli et al. (2011) discutem, ademais, essa relação e apresentam resultados de $\mathrm{R} \$ 416,50 /$ ha para a região Nordeste e uma média nacional de $\mathrm{R} \$ 530,10 /$ ha. Essa grande disparidade entre as médias apresentadas pelos autores e as exibidas pelo G2 está relacionada com o excelente aproveitamento da SAU dos territórios aglomerados nesse grupo que gerou uma das mais elevadas rendas.

De acordo com Guanziroli et al. (2011), o aproveitamento máximo da SAU é necessário porque as UFs não podem dar-se ao luxo de deixar áreas sem explorar; assim, esses atores as utilizam de diversas maneiras e com produções diversificadas. Portanto, a interação entre a energia e a informação nos territórios aglomerados no G2, assim como no G1 e G4, conseguiu ir além de seus objetivos, permitindo até mesmo a possibilidade de realização de investimentos na unidade familiar.

\section{Tessituras, nós e redes}

Ao se discutirem os atores sintagmáticos e suas relações socioeconômicas e produtivas, conseguiu-se, de maneira mais clara e objetiva, identificar os fatores que compõem imagens territoriais específicas.

Considerou-se então, para uma compreensão ao menos parcial das imagens territoriais, que o trabalho exercido pela família rural do distrito do Trici em Tauá é a principal ação e o ator sintagmático é a própria família, que cria, "delimita”, trabalha, produz e estabelece uma relação de poder, territorializando o espaço através do trabalho para se reproduzir por intermédio da natureza e dela extrair grande parte das suas fontes de subsistência. Portanto, compreende-se que os principais objetivos 
que entrelaçam a energia e a informação nas unidades familiares em estudo são a subsistência familiar e, posteriormente, a comercialização do possível excedente como meio para adquirir outras mercadorias, igualmente necessárias à satisfação de necessidades (Oliveira, 2011). Como observado, entende-se a energia como todo o trabalho exercido e toda a sua capacidade de transformar a natureza (Marx, 1984) e a informação como um conjunto de conhecimentos, saberes e práticas exercidas ou adquiridas pelas famílias rurais, em função da subsistência familiar (Raffestin, 1993).

A combinação dessa energia e informação demonstra a relação de poder exercida; portanto, o poder que as famílias rurais exercem nos seus respectivos territórios está enraizado no trabalho e nas técnicas adquiridas com a experiência, que permitem aprimorar a base de recurso e a eficiência produtiva (Idem). Essas relações de poder, tal como previamente colocado, originam-se da associação do sistema de três subconjuntos estruturais, a saber: as tessituras, os nós e as redes. As tessituras, que correspondem à área de exercício do poder ou ao enquadramento deste, são compreendidas aqui como a superfície total das unidades familiares; os nós ou pontos simbolizam a posição/localização das unidades familiares no semiárido do distrito do Trici; a rede é a comunidade que se organiza via sindicatos, associações ou cooperativas, garantindo a comunicação e a troca de experiência entre os territórios. Juntos, esses elementos do espaço dão suporte à existência da unidade familiar, que é o próprio território. Interpretando esse conjunto de relações, encontram-se a origem e a dinâmica do poder e, consequentemente, o cerne da produção desse território.

Em suma, as relações estabelecidas entre os atores sintagmáticos, a terra e o poder permitiram a reprodução desses territórios e da ideia de agricultura familiar, mesmo que algumas regiões tenham apresentado limitações.

\section{Considerações finais}

À medida que os membros da família rural conseguem ampliar a renda, seu território é fortalecido e sua sustentabilidade aumentada, pois a renda extra é revertida em infraestrutura e em melhoramento das superfícies disponíveis e das produções, até mesmo daquelas que não têm influência relevante na produção total. As outras produções e a criação de animais não ruminantes apresentaram baixos resultados em todas as unidades familiares estudadas, portanto em todos os grupos de imagens territoriais; já a produção de pequenos ruminantes teve resultados superiores, porém com pouca influência na renda anual.

A análise permitiu identificar cinco grupos de imagens territoriais que possuem sistemas de relações produtivas diferentes, além de apresentarem conjuntos de relações que viabilizam a territorialidade e que dão conteúdo aos territórios. Portanto, 
os resultados da análise de agrupamento possibilitaram compreender a imagem territorial e, consequentemente, a estrutura profunda desses territórios familiares.

\section{Referências Bibliográficas}

Altieri, M. A. \& Nicholls, C. I. (2002), “Un método agroecológico rápido para la evaluación de la sostenibilidad de cafetales". Manejo Integrado de Plagas y Agroecología, 64: 17-24.

Alves, C. L. B. \& Paulo, E. M. (2012), "Mercado de trabalho rural cearense: evolução recente a partir dos dados da PNAD". Abet, 2 (11): 47-61.

Andrade, V. de; Lima, L. C. (2011), "Inovações técnicas da caprinocultura em Tauá no contexto da reestruturação socioespacial do Ceará”. Revista Homem, Espaço e Tempo, 1: 67-85.

Asabrasil - Articulação do Semiárido Brasileiro. (2014), “Semiárido”. Disponível em http://www.asabrasil.org.br/Portal/Informacoes.asp?COD_MENU=105, consultado em 19/6/2014.

Antonino, A. C. D. et al. (2000), "Balanço hídrico em solo com cultivos de subsistência no semiárido do Nordeste do Brasil”. Revista Brasileira de Engenharia Agrícola e Ambiental, $4(1): 29-34$.

Araújo, J. C. et al. (2008), "Estudo socioeconômico sobre agricultores familiares produtores de queijo-de-coalho das comunidades do Junco, Tiassol e Tapera no município de Tauá, CE”. Trabalho apresentado no XLVI Congress of the Rural Economy and Sociology Society, Rio Branco, Acre, Brasil.

$\mathrm{BACH}, \mathrm{B}$. et al. (2003), "Economic analysis of different farming systems on the individual level in the Northeast of Brazil". In: GAISER, T. et al. (eds.). Global change and regional impacts. Berlim, Springer, pp. 359-374.

Caron, P. \& Hubert, B. (2003), “Dinâmica de sistemas de pecuária”. In: Caron, P. \& SABOURIN, E. (eds.). Camponeses do sertão: mutação das agriculturas familiares no Nordeste do Brasil. Brasília, Embrapa/Informação Tecnológica, pp. 103-122.

Chayanov, A. (1974), La organización de la unidad económica campesina. Buenos Aires, Nueva Visión.

Cordonnier, P. (1963), Modelisation de l'exploitation agricole: études d'économie rurale. Paris, Département des Relations Extérieures et Information de la Société des Pétroles Shell Berre.

Elias, D. (2003), “Desigualdade e pobreza no espaço agrário cearense”. Mercator, 2 (3): 61-69.

FERnANDes, B. M. et al. (orgs.). (2009), Lutas camponesas contemporâneas: condiçôes, dilemas e conquistas. São Paulo, Editora da Unesp.

FrançA, C. L. de et al. (orgs.). (2002), Aspectos econômicos de experiências em desenvolvimento local. São Paulo, Instituto Pólis. 
Gomes, M. C. (2010), Canafistula: vida e esperança no sertão nordestino: estudo sobre a experiência de desenvolvimento local na organização socioeconômica do povoado de Canafistula, Apuiarés, $C E$. Ceará, dissertação de mestrado, Universidade Estadual do Ceará (Uece).

Guanziroli, C. E. et al. (2011), Agricultura familiar no Nordeste: uma análise comparativa entre dois censos agropecuários. Fortaleza, Banco do Nordeste do Brasil.

Guimarães Filho, C. (2005), "Diagnósticos, capacitações e projetos-piloto em apoio ao desenvolvimento territorial". Trabalho apresentado no I Fórum Regional de Economia Agrícola. Petrolina, Sociedade Brasileira de Sociologia e Economia Rural (Sober).

Haesbaert, R. (2001), "Da desterritorialização e multiterritorialidade". Rio de Janeiro. Anais do V Congresso da Associação Nacional de Pós-Graduação e Pesquisa em Planejamento Urbano e Regional, Anpur, n. 3 .

Heredia, B. M. A. de. (1979), A morada da vida: trabalho familiar de pequenos produtores do Nordeste do Brasil. Rio de Janeiro, Paz e Terra.

Holanda Junior, E. V. (2006), Sistemas de produção de pequenos ruminantes no semiárido do Nordeste do Brasil. Sobral, Embrapa Caprinos.

IBGE - Instituto Brasileiro de Geografia e Estatística (2007), "Produção agrícola municipal: lavoura temporária”. Disponível em http://www.cidades.ibge.gov.br/comparamun/compara. php?lang $=\&$ coduf $=23 \&$ idtema $=100 \& \operatorname{codv}=V 124 \&$ order $=$ dado $\&$ dir $=$ desc $\&$ lista $=u f \& c$ ustom $=$, consultado em 19/6/2014.

(2010), “Censo demográfico 2010”. Disponível em http://www.ibge.gov.br, consultado em $19 / 6 / 2014$

IPECE - Instituto de Pesquisa e Estratégia Econômica do Ceará. (2014), "Perfil básico municipal”. Disponível em http://www.ipece.ce.gov.br/publicacoes/perfil_basico/pbm-2014/ Taua.pdf, consultado em 1/11/2015.

(2010), "Perfil básico municipal". Disponível em http://www.ipece.ce.gov.br/publicacoes/perfil_basico/pbm-2010/Taua.pdf, consultado em 19/6/2014.

. (2011), "Perfil básico municipal". Disponível em http://www.ipece.ce.gov.br/publicacoes/perfil_basico/pbm-2011/Taua.pdf, consultado em 19/6/2014.

Lima, L. C. et al. (2011), Os novos espaços seletivos no campo. Fortaleza, Eduece.

Lopes, E. S. A. (2009), “A pluriatividade na agricultura familiar do estado de Sergipe”. In: LoPES, E. S. A \& COSTA, J. E. da (orgs.). Territórios rurais e agricultura familiar no Nordeste. Aracaju, Edufs, pp. 103-186.

Maneschy, M. C. \& Klovdhal, A. L. (2007), "Redes de associações de grupos de camponeses na Amazônia Oriental (Brasil): fontes de capital social?". Redes, Revista Hispano para el Análisis de Redes Sociales, 4 (2).

MARX, K. (1984), “Trabalho alienado e superação positiva da autoalienação humana”. In: Fernandes, Florestan (org.). Marx \& Engels. São Paulo, Ática.

Menezes, A. J. A. (2002), Análise econômica da produção invisivel nos estabelecimentos agrícolas 
familiares no Projeto de Assentamento Agroextrativista Praia Alta e Piranheira, Municipio de Nova Ipixuna, Pará. Pará, dissertação de mestrado, Universidade Federal do Pará.

Neumann, P. S. \& Silveira, P. R. (2000). “A capacidade de reprodução de agricultores familiares na região de Santa Maria/Rs”. Anais do Congresso Mundial de Sociologia Rural, n. 38, cd-rom.

Norder, L. A. C. (2014), "Controvérsias sobre a reforma agrária no Brasil (1934-1964)”. Revista Nera, 17 (24): 133-145.

Oliveira, A, M. (2011), "Produção camponesa e sustentabilidade no campo: unidade camponesa em assentamentos no Ceará’. In: Silva. E. V. da et al. (orgs.). Planejamento ambiental e bacias hidrográficas. Fortaleza, Edições UFC, pp. 129-157.

Ploeg, J. D. V. (2009), “Sete teses sobre a agricultura camponesa”. In: Peterson, P. (org.). Agricultura familiar camponesa na construção do futuro. Rio de Janeiro, AS-PTA, pp.17-32.

Raffestin, C. (1993). Por uma geografia do poder. São Paulo, Ática.

Ratzel, E. (1988), Géographie politique. Paris, Difusion Economique.

Rodrigues, I. V. (2006), A propensão à desertificação no Estado do Ceará: análise dos aspectos agropecuários, econômicos, sociais e naturais. Fortaleza, dissertação de mestrado, Universidade Federal do Ceará.

Rogerson, P. A. (2012), Métodos estatísticos para geografia: um guia para o estudante. 3. ed. Trad. P. F. B Carvalho e J. I. R. Rigotti. Porto Alegre, Bookman.

SACK, R. (1986), Human territoriality. Cambridge, Cambridge University Press.

SAntos, M. A. (1997), A natureza do espaço: técnica e tempo, razão e emoção. 2. ed. São Paulo, Hucitec.

Schneider, S. (2003), Políticas públicas, pluriatividade e desenvolvimento rural no Brasil. Porto Alegre, UfRGS.

Shanin, T. (2008), "Lições camponesas". In: Paulino, E. T. \& Fabrini, J. E. Campesinato e territórios em disputa. São Paulo, Expressão Popular, pp. 23-48.

SousA, I. S. et al. (2005), "Manejo agroecológico de árvores algodoeiras: uma alternativa para famílias rurais de pequena dimensão no semiárido do Ceará”. Revista Ceres, 52 (303): 787-809.

Souza Neto, J. et al. (1995), "Análise socioeconômica da exploração de caprinos e ovinos no Estado do Piauí”. Pesquisa Agropecuária Brasileira, 30 (8): 1017-1030.

Tourraund, J. F. et al. (1993), Pesquisa sobre sistemas de produção no semiárido: o caso do município de Tauá-Ceará. Sobral, Embrapa Caprinos.

VIDAL, D. de L. (2010), "Diversidade forrageira na região semiárida do Ceará, Brasil: componentes estruturais”. Revista Portuguesa de Ciências Veterinárias, 105 (573-576): 53-61.

. (2013), "Work division in family farm production units: feminine responsibilities typology in a semi-arid region of Brazil". Journal of Arid Environments, (97): 242-252.

VidAl, D. de L. \& AlenCAR, J. V. de O. de. (2009), "Diferenciação camponesa na depressão sertaneja semiárida do Ceará”. Revista Nera, 15 (12): 106-135. 


\section{Resumo}

Realidade territorial de unidades familiares no semiárido brasileiro

O crescente interesse em dinâmica da (re)produção familiar advém sua importância para o desenvolvimento do setor agrário brasileiro. Para a compreensão da dinâmica do território familiar no semiárido brasileiro o estudo englobou 96 unidades familiares (UFs) de seis comunidades rurais (Tauá-CE). Variáveis e análises que apreendessem atributos da dinâmica socioeconômica das UFs como reflexo da capacidade dos atores sintagmáticos de transformar a natureza por meio de relações produtivas foram realizadas. Identificaram-se grupos de imagens territoriais que possuem sistemas de relações produtivas diferentes e que viabilizam a territorialidade.

Palavras-chave: Agricultura familiar; Imagens territoriais; Dinâmica socioeconômica.

\section{Abstract}

Territorial reality of rural households in the Brazilian semiarid

The growing interest in the dynamics of family (re)production comes from of this importance to the development of the Brazilian agricultural sector. In order to proposing some parameters for understanding the dynamics of semiarid Ceará familiar territory, the study included 96 households from six Communities (municipality of Tauá-CE). Indicators and analyzes which seize the socioeconomic dynamics of the households and reflecting the ability of syntagmatic actors to transform nature through productive relationships were elaborated. "Groups of Territorial Images" that have diverse productive relations systems were identified. Keywords: Family Farming; Territorial images; Socioeconomic dynamics.

Texto enviado em 24/10/14 e aprovado em 24/3/15. DOI: 10.11606/0103-2070.ts.2016.105992. Déa de Lima Vidal é professora adjunta da Universidade Estadual do Ceará (Uece), onde coordena o Laboratório de Estudos em Sistemas Agrários Semiáridos (Lesisa), e docente permanente na linha de pesquisa em Desenvolvimento Sustentável do Mestrado Acadêmico em Logística e Pesquisa Operacional (Geslog) da Universidade Federal do Ceará (UFC).E-mail: dea.vidal@uece.br. Daniel Paraguay Alves Santos é bacharel em geografia pela Universidade Estadual do Ceará (Uece).E-mail: lesisa2008@gmail.com. 